\title{
Vant: Um estudo sobre a utilização de Veículo Aéreo não Tripulado na Agricultura de Precisão
}

CHIACCHIO, Simon Skarabone Rodrigues [1], TEIXEIRA, Bruno Eduardo [2], TECH, Adriano Rogério Bruno [3]

CHIACCHIO, Simon Skarabone Rodrigues; TEIXEIRA, Bruno Eduardo; TECH, Adriano Rogério Bruno. Vant: Um Estudo Sobre a Utilização de Veículo Aéreo Não Tripulado na Agricultura de Precisão. Revista Científica Multidisciplinar Núcleo do Conhecimento. Ano 01, Ed. 01, Vol. 12, Pp. 79-89, dezembro de 2016. ISSN: 2448-0959

\section{RESUMO}

O presente artigo tem como objetivo apresentar elementos de análise na utilização de VANT na agricultura de precisão. Entendemos que o momento é propício para a implantação e desenvolvimento de atividades de monitoramento e gestão na agricultura. O método utilizado para a elaboração do estudo foi o levantamento bibliográfico sobre a temática, a utilização de artigos e estudos nacionais e internacionais sobre as tecnologias de VANT na atividade agroindustrial e também a elaboração de um VANT para as atividades de sobrevoo e mapeamento de solo, lavoura e plantio. Os resultados se mostraram favoráveis para a utilização e para a aferição em diferentes níveis e objetivos do ponto de vista da gestão eficiente da agricultura de precisão.

\section{INTRODUÇÃO}

Nos últimos anos muitos são os esforços para que as atividades agroindustriais sejam administradas de maneira integrada e que essa integração gere ao produtor dados confiáveis para a tomada de decisão.

As novas tecnologias, e soluções de diferentes frentes são nesse contexto elementos que podem atender esse anseio do produtor e do administrador dessas atividades produtivas.

Uma tecnologia relativamente nova na atividade agroindustrial do Brasil é a utilização do VANT, essa tecnologia já bastante difundida em países desenvolvidos, passa a ser uma cada vez mais presente nessa atividade produtiva. 


\section{HISTÓRICO DO VANT}

A história dos Veículos Aéreos não Tripulados é muito antiga, os primeiros VANTs foram registrados a muito tempo. Conforme Alves Neto (2010), uma das primeiras referências sobre o desenvolvimento de Veículos Aéreos Não-Tripulados no mundo é atribuída a um brasileiro, o padre Bartolomeu de Gusmão.

De acordo com Brandão (2007 apud LONGHITANO, 2010, p.8) o padre Bartolomeu de Gusmão construiu um balão de ar quente e demonstrou em 1709 em Portugal ao rei João Quinto e toda a corte real.

O primeiro voo aéreo fotografado de que se tem registro é de 1888, na França realizado por Arthur Batat, através de uma câmera fotográfica acoplada em uma pipa, conforme (PUSCOV, 2002 apud MEDEIROS, 2007, p. 19).

Sobre a atividade de rádio controle da aeronave, o primeiro VANT foi desenvolvido por Reginald Denny em 1935 e a partir dai teve início o aperfeiçoamento (MEDEIROS, 2007, p. 19).

O VANT hoje possui uma característica de utilização direcionada ao meio militar e tiveram seu desenvolvimento expressivo nessa área.

No ano de 1982 Israel conseguiu destruir 16 das 17 baterias antiaéreas Sírias, depois da utilização e mapeamento aéreo realizado por um VANT, a Guerra do Líbano é considerado por pesquisadores o marco histórico da utilização de VANTs para essa finalidade (SILVEIRA, 2005 apud MEDEIROS, 2007, p. 21).

Outra utilização do VANT ocorreu em 2002 na guerra do Afeganistão, nessa ocasião nota-se emprego de combate e não somente o de reconhecimento.

Em 2002, ficou conhecido o Veículo Aéreo Não Tripulado americano, "Predator", que foi utilizado durante a guerra do Afeganistão. Esse foi considerado o primeiro emprego real de um veículo não tripulado com o lançamento de míssil (MEDEIROS, 2007, p. 21).

No Brasil, a história do VANT é mais recente, teve seu início na década de 1980, quando o Centro Técnico Aeroespacial (CTA), desenvolveu o projeto Acauã (MEDEIROS, 2007, p. 21).

\section{AVIAÇÃO NA AGRICULTURA}

De acordo com Couto (2007), a aviação agrícola foi inventada pelo agente florestal alemão Alfred Zimmermann em 1911, mas só teve aplicação comercial nos EUA, em 1921.

De acordo com estudos de Zica et al. (2005 apud Rasi, 2008, p. 22) a aviação agrícola no Brasil, teve seu início em 1947 no Rio Grande do Sul, na região de Pelotas onde foi realizado o primeiro voo agrícola no país em agosto daquele ano devido ao fato de ter tido uma praga de gafanhotos.

O dia 19 de agosto foi instituído como o dia nacional da aviação agrícola no Brasil Rasi (2008), desde os primeiros períodos de utilização, a agricultura vem transformando suas atividades de controle de pragas e 
monitoramento com a finalidade de manter eficiência no processo produtivo agroindustrial.

\subsection{A AGRICULTURA E A TECNOLOGIA}

Segundo Balsan (2006), a partir da década de 60, assistimos um processo de modernização da agricultura brasileira, nessa década, com a modernização da agricultura, surgem novos objetivos e formas de exploração agrícola e gestão na agroindústria.

A modernização da agricultura tem provocado um desenvolvimento na em todas as atividades industriais do setor. A expansão da agricultura "moderna" ocorre concomitante a constituição do complexo agroindustrial, modernizando a base técnica dos meios de produção, alterando as formas de produção agrícola e gerando efeitos sobre o meio ambiente. O desenvolvimento da agricultura nos faz refletir sobre a realidade do agronegócio, pois esse desenvolvimento não atinge todos os produtores.

Pensar sobre as tendências do "novo mundo rural" requer que se volte o olhar para esta realidade que, ao mesmo tempo em que tem colocado uma classe da sociedade com o que há de mais moderno na agricultura e pecuária, contraditoriamente, deixa outra, como os agricultores familiares, ou seja, a maioria dos produtores rurais, cada vez mais distantes de tais inovações (BALSAN, 2006, p. 125).

A tecnologia do VANT, atende como destaca Balsan (2006), o que é distante na realidade da agricultura familiar, uma vez que esses equipamentos (VANTs), atendem no quesito preço e manutenção uma solução de baixo custo e de retorno considerável em termos de levantamento e coleta de dados para a atividade industrial como um todo.

\subsection{A AGRICULTURA DE PRECISÃO}

A concepção da agricultura de precisão se desenvolveu na Europa, e em seguida nos Estados Unidos, foi uma atividade que se desenvolveu como forma de amenizar os prejuízos causados pela agricultura ao meio ambiente (MEDEIROS, 2007, p.5).

A dosagem dos insumos para maximizar a produção, sem a necessidade de ultrapassar os valores dos defensivos ou fertilizantes aplicados nas lavouras, e não colocar em risco a qualidade da água, foi o principal fator para a busca dessa tecnologia (MOLIN, 2001 apud MEDEIROS, 2007, p.5).

De acordo com Molin (2013) o primeiro passo para determinante para a implantação da agricultura de precisão (AP) foi dado por meio do surgimento do Sistema de Posicionamento Global por Satélite (GPS) em meados de 1990, já no Brasil as atividades datam de 1995 com a chegada de equipamentos especialmente colhedoras equipadas com monitores de propriedade, o autor destaca que

A AP tem várias formas de abordagem, mas o objetivo é sempre o mesmo - utilizar estratégias para resolver os problemas da desuniformidade das lavouras e se possível tirar proveito dessas desuniformidades. São práticas que podem ser desenvolvidas em diferentes níveis de complexidade e com diferentes objetivos (MOLIN, 2013, p.5).

O autor destaca uma atividade relevante quando o assunto é verificar a precisão e eficiência no plantio e consequentemente na colheita, quando se realiza um sobrevoo nas lavouras em baixa altitude, é possível 
aferir as falhas no processo de plantio ou mesmo problemas no desenvolvimento da plantação.

Se as atividades descritas fossem realizadas com aeronaves de pequeno porte e sobre toda a área plantada, o custo operacional da atividade produtiva tornaria inviável a utilização dessa ferramenta (aeronave tripulada), com o uso de VANT, essa atividade pode ser facilmente observada e o custo final do processo de produção não sofre alteração significativa, tornando assim viável o uso e aplicação dessa ferramenta.

No exemplo abaixo é possível verificar a área a ser plantada e que deverá receber o plantio conforme as atividades agrícolas que já estão definidas para o terreno.

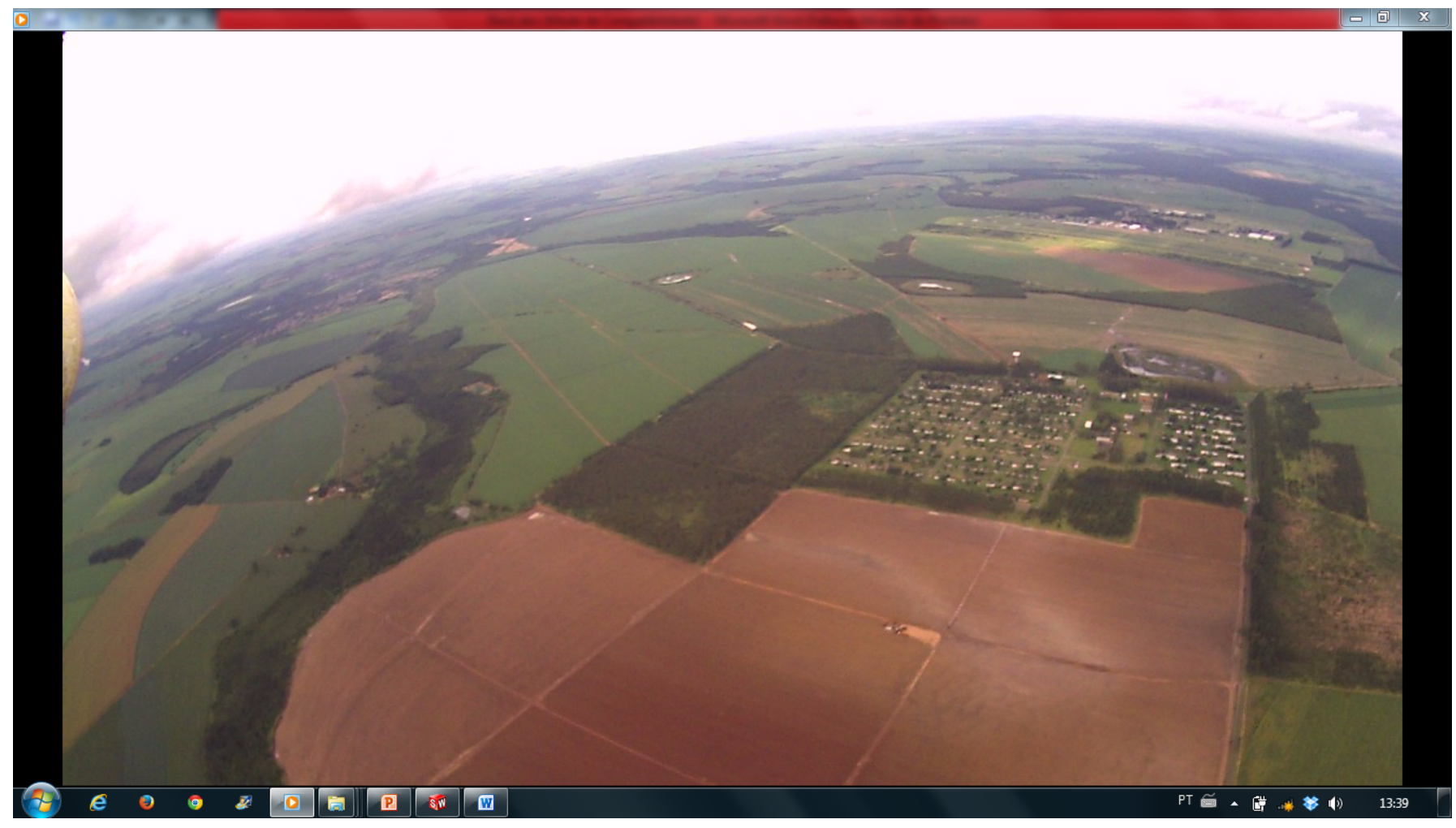

Figura 1- Foto aérea $\mathrm{n}^{\circ} 1$ - VANT $\mathrm{n}^{\circ} 8$. Fonte: arquivo pessoal 


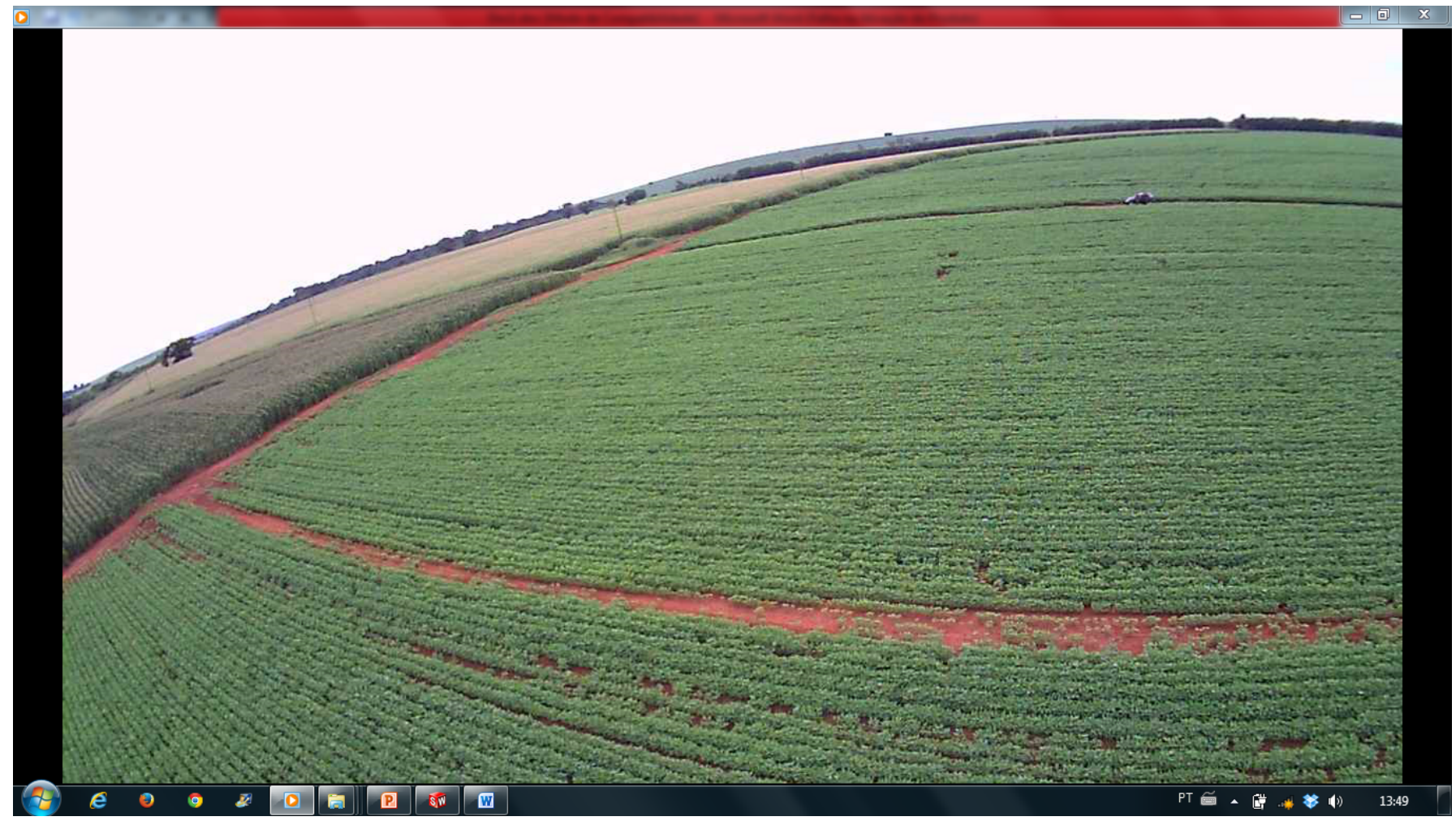

Figura 2- Foto aérea $\mathrm{n}^{\circ} 2$ - VANT n 8 . Fonte arquivo pessoal

Na segunda tomada, a foto $\mathrm{n}^{\circ} 2$, é possível verificar a falha no processo de plantio ou no desenvolvimento previsto para a atividade de colheita, em uma primeira aferição é possível identificar a falha e pelo seu tamanho e extensão é facilmente confundida com uma via de acesso, no entanto, refere-se a uma falha de plantio muito comum nessa atividade agrícola. É possível notar pela tomada aérea a extensão, e dependendo do processo de gestão, adotar medidas corretivas, no entanto esse levantamento sem o auxílio da aeronave VANT não seria possível, ou mesmo, o real tamanho e complexidade das ações corretivas poderiam ser interpretadas de maneira equivocada pelo produtor.

Quando o produtor é considerado de grande porte é possível dizer que essa perda já é prevista considerando todo processo produtivo, no entanto, ao comparar com uma atividade produtiva rural familiar essas pequenas falhas podem significar e comprometer muito as atividades produtivas do pequeno produtor.

Conforme Coelho (2005), entre os aspectos englobados pela agricultura de precisão estão a variabilidade dos solos, clima, diversidade de culturas, performance de máquinas agrícolas e insumos naturais ou sintéticos utilizados no desenvolvimento de culturas.

As novas tecnologias impulsionaram o desenvolvimento da Agricultura de Precisão e possibilitaram sua aplicação hoje, podemos citar como exemplo a utilização de sistemas de sensoriamento remoto, levantamento de dados de faixa produtiva entre outros.

\subsection{SENSORIAMENTO REMOTO}

Segundo Moran et al. (1997 apud Coelho 2005, p.17), a aquisição de informações sobre algum objeto sem estar em contato físico direto pode ser definido como sensoriamento remoto. 
No campo da agricultura, a tecnologia de sensoriamento remoto tem sido usada para uma variedade de aplicações, que vão desde a avaliação do estado nutricional e hídrico em plantas até a detecção de plantas daninhas e insetos (COELHO, 2005, p.17).

Podemos citar como uma forma de sensoriamento que está em processo de desenvolvimento é a utilização de veículos aéreos não tripulados, para acompanhamento de plantações através da obtenção de imagens.

Os diferentes usos dos equipamentos sejam eles de asa fixa ou de asa rotativa, pode de maneira específica atender as mais diferentes necessidades do produtor rural, gerente de projetos e/ou administrador de atividades agrícolas, gestores de parques ecológicos, em suma, há diferentes atividades que podem ser auxiliadas para a atividade produtiva agroindustrial com o uso do VANT e os aplicativos que estão disponíveis para gerenciamento.

No exemplo abaixo é possível identificar o mapeamento de solo, efluentes e plantações que com o uso da imagem feita pelo VANT auxilia na atividade produtiva e no gerenciamento remoto.

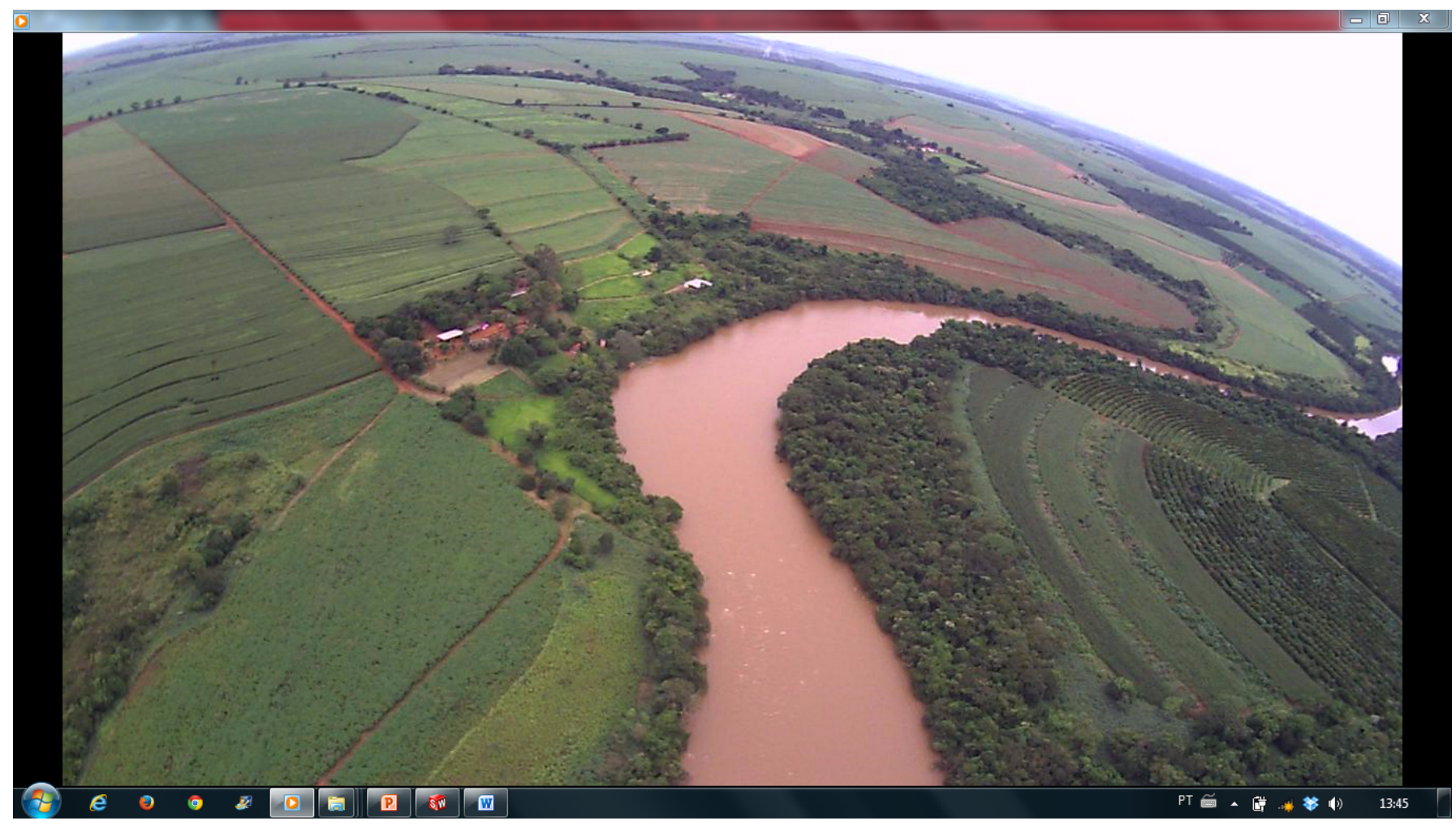

Figura 3- Foto aérea $n^{\circ}$ 3: VANT nº8. Fonte: arquivo pessoal, região de Pirassununga 


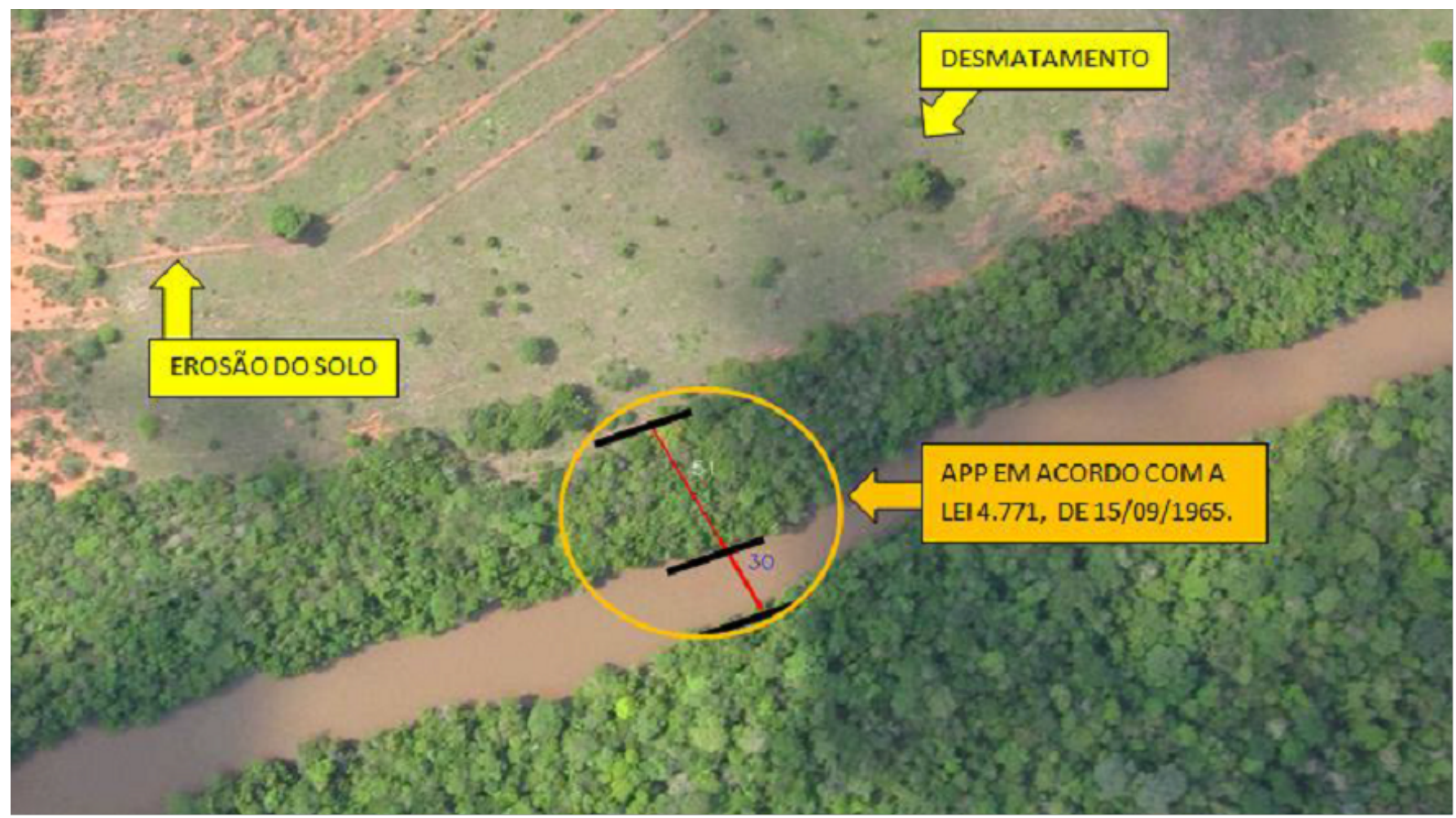

Figura 4- Tomada aérea por VANT - mapeamento ambiental. Fonte: Dalbelo 2013

No levantamento feito pelo VANT n 8 no exemplo apresentado, é possível fazer uma série de análises técnicas e mapeamento das atividades de plantio, desmatamento, erosão de solo, nível de recuo da margem, atendimento de acordo com a legislação vigente entre outros itens inerentes a gestão ambiental e de produção agrícola.

De acordo com Dalbelo (2013) esses levantamentos são possíveis devido ao mapeamento e gerenciamento que a captura de imagem pode fazer. $\mathrm{O}$ baixo custo atrelado a atividade produtiva rural, pode viabilizar a gestão e o gerenciamento das atividades como um todo. Um desafio da agricultura de precisão é a tomada de decisão, com base em informações reais, e produzidas com confiabilidade e rapidez favorecem na gestão eficiente das atividades de gerenciamento remoto.

Outra utilização do VANT que pode ser facilmente introduzida nas diversas atividades produtivas é o monitoramento remoto de atividade de construção, reforma, mapeamento e fotometria.

No exemplo abaixo é possível com o sobrevoo de reconhecimento fazer o levantamento preciso do status da obra e dessa forma munir os gestores de informações para a tomada de decisão. 

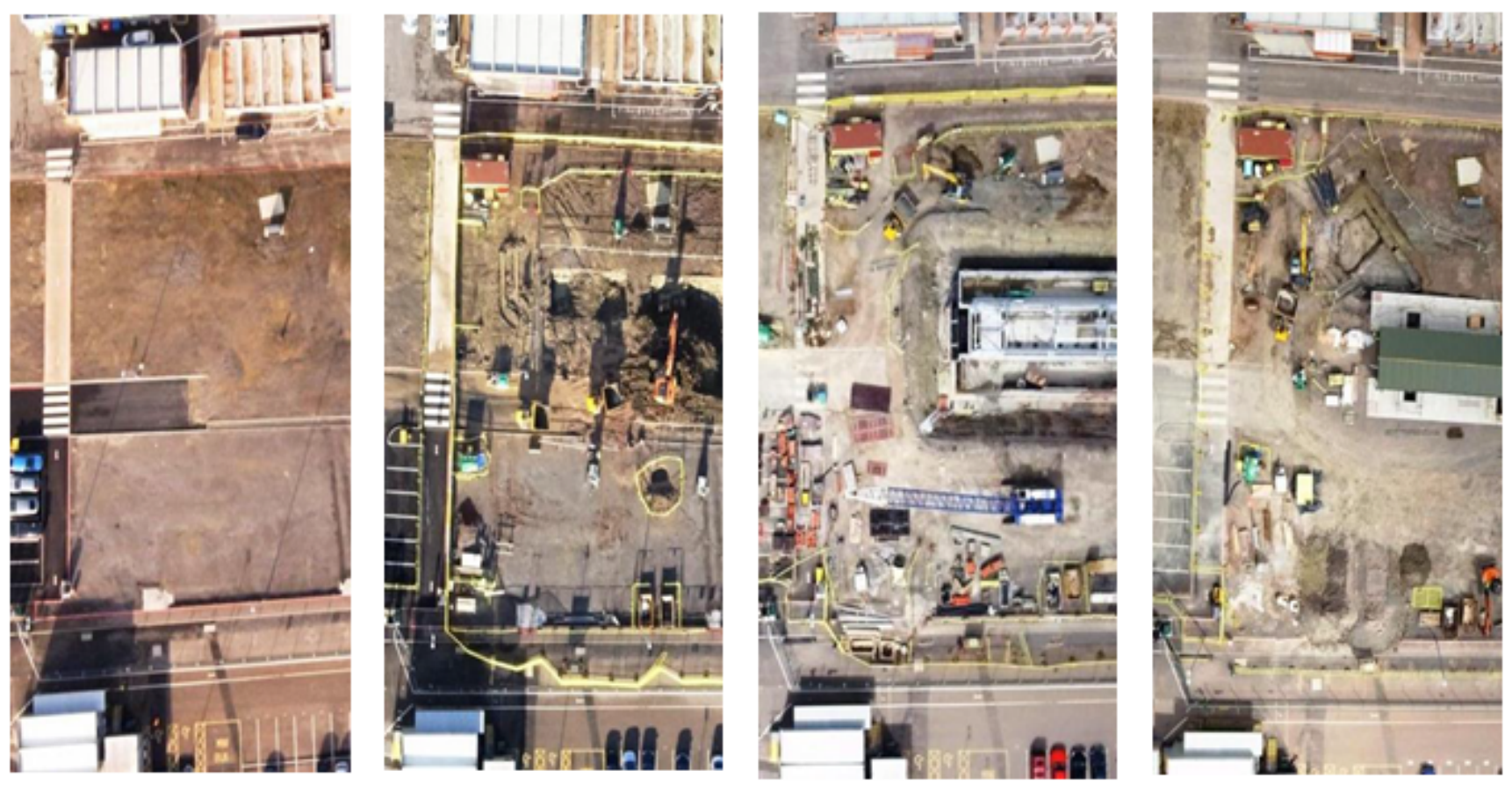

Figura 5- Tomada aérea. Fonte: Dalbelo 2013

A atividade descrita, é um exemplo de atividade que pode ser aplicada pela adoção da técnica de monitoramento de área aberta, nesse exemplo é possível monitorar pela atividade remota o andamento das diferentes atividades na construção e com essas atividades munir os gestores na tomada de decisão, e consequentemente trabalhar com precisão o status da obra e interagir corretivamente de acordo com a necessidade.

A crescente utilização de VANTs para monitoramento vem crescendo devido a novas tecnologias, essas novas tecnologias favorecem o desenvolvimento de soluções prática e mais baratas para antigas demandas e necessidades agrícolas.

Avanços recentes na tecnologia computacional, desenvolvimento de software, materiais mais leves, sistemas globais de navegação, avançados links de dados, sofisticados sensores e a miniaturização são os motivos do aumento de desenvolvimentos de VANTs (JORGE; INAMASU e DO CARMO, 2011, p.399).

Diante do exposto, o autor salienta que frente as demandas e com o auxílio de todo aparato tecnológico, a viabilidade dos mais diferentes usos do VANT tem se mostrado eficiente no atendimento das necessidades desde o processo de produção até o gerenciamento dos dados.

Vários países vêm desenvolvendo pesquisas relacionadas a veículos aéreos não tripulados. Com relação a aplicação de VANTs no campo da pulverização, mapeamento e outras aplicações na agricultura o Japão se destaca (Simpson, 2003; De Garmo, 2004 apud JORGE; INAMASU e DO CARMO, 2011, p.399).

Os sistemas autônomos estão se tornando mais sofisticados e confiáveis. VANTs, em virtude da sua capacidade para assumir as missões de alto risco e seu potencial para operações de baixo custo em relação à aeronave tripulada, tem se tornado uma proposta ideal para o desenvolvimento de novas tecnologias (JORGE; INAMASU e DO CARMO, 2011, p.399). 
Segundo o autor por se apresentarem mais confiáveis e sofisticados, os sistemas autônomos, apresentam condições para assumir as missões de alto risco e seu potencial para operações de baixo custo em relação à aeronave tripulada, vem se apresentado como uma proposta ideal para o desenvolvimento de novas tecnologias.

As diferentes atividades produtivas, e a grande demanda por informações confiáveis para a gestão eficiente nesse contexto de atividade torna-se então uma oportunidade para com a utilização do VANT sanar antigos desafios.

A utilização desse tipo de equipamento no monitoramento em vários ramos da agricultura pode ser de grande importância e utilização conforme descrito por Moran et al. (1997; MOLIN, 1997 apud JORGE, 2003, p. 1).

O monitoramento por imagens aéreas na agricultura tem provado ser útil para uma série de objetivos, tais como: qualidade de plantio, emergência ou brotamento da cultura; mapeamento de plantas invasoras; densidade de palha sobre o solo; zoneamento de solos e de áreas homogenias de manejo; drenagem natural da parcela; amostragem de solo orientada; crescimento e desenvolvimento da cultura até à maturação; previsão de safra; avaliação da densidade da copa ou vigor da cultura; dentre outras.

Dentro os vários tipos de utilização dos veículos aéreos não tripulados pode-se citar a possibilidade de voo remoto, ou seja, pilotagem com visão direta da aeronave e voo autônomo quando não precisamos da visão direta da aeronave.

As diferentes modalidades de voo, ou seja, o tipo de pilotagem, pode atrelado as técnicas de coleta de dados subsidiar os produtores ao gerenciamento e o desenvolvimento da cultura. As atividades produtivas e demandas dessa atividade são supridas nas mais diferentes frentes de atuação, quando a necessidade é atender de forma prática, rápida e confiável a necessidade desse setor produtivo.

\section{CONSIDERAÇÕES FINAIS}

Por meio dos levantamentos realizados na pesquisa e pelas análises de imagem e utilização de parâmetros de qualidade de plantio na produção de lavouras, foi possível ratificar a eficiência nas atividades de monitoramento e mapeamento dos solos realizados pelo VANT n ${ }^{\circ} 8$.

Outras atividades que foram possíveis nos sobrevoos foram: a demarcação de área plantadas; qualidade de plantio; mapeamento de plantas invasoras; drenagem natural da parcela; erosão entre outros elementos destacados no trabalho.

Concluímos no estudo que a utilização do VANT além de atender as diferentes demandas do produtor rural, favorece na eficiência na tomada de decisão dos gestores, isso é possível pelo fato das tecnologias serem integradas, ou seja, os diferentes aplicativos disponíveis para o tratamento das imagens transmitidas e/ou coletadas pelo VANT dão a inovação da agricultura de precisão novos rumos ao processo de produção e desenvolvimento nos dias de hoje e se projeta grande avanço para o futuro da agroindústria.

\section{REFERÊNCIAS}


ALVES, Olinda De Lima Farias. Planejamento e Controle de Missões de um VANT de asa fixa. 2010. 113 f. Dissertação (Mestrado) - Instituto Militar de Engenharia, Rio de Janeiro, 2010.

BALSAN, Rosane. Impactos decorrentes da modernização da agricultura brasileira. Campo-território: Revista de Geografia Agrária, Paraná, v. 1, n. 2, p.123-151, ago. 2006. Semestral. Disponível em: <http://www.seer.ufu.br/index.php/campoterritorio/article/view/11787/8293>. Acesso em: 11 abr. 2014.

COELHO, Antônio Marcos. Agricultura de Precisão: Manejo da variabilidade espacial e temporal dos solos e culturas. Sete Lagoas: Embrapa, 2005. ISSN 1518-4277. Disponível em: <http://ainfo.cnptia.embrapa.br/digital/bitstream/CNPMS/18887/1/Doc_46.pdf>. Acesso em: 15 abr. 2014.

COUTO, J.L.V. AVIAÇÃO

AGRÍCOLA. 2007. Disponível

em:

<http://www.ufrrj.br/institutos/it/de/acidentes/aviao.htm>. Acesso em: 15 abr. 2014.

DALBELO, Luiz. VANT e Suas Aplicações. 2013. Disponível em: <http://mundogeoconnect.com/2013/arquivos/palestras/19_jun-cd-luiz-dalbelo.pdf>. Acesso em: 09 abr. 2014.

JORGE, Lúcio André de Castro. Metodologia para Utilização de Aeromodelos em Monitoramento Aéreo: Análise de Imagens. São Carlos, 2003. ISSN 1517-4778. Disponível em: <file:///C:/Users/Du/Downloads/CiT18_2003.pdf>. Acesso em: 12 abr. 2014.

JORGE, Lúcio André de Castro Lúcio; INAMASU, Ricardo Yassushi; do Carmo, Rhendrix Borges. Desenvolvimento de um VANT totalmente configurado para aplicações em Agricultura de Precisão no Brasil. In SIMPÓSIO BRASILEIRO DE SENSORIAMENTO REMOTO - SBSR, 15., 2011, Curitiba. Anais. Curitiba: Inpe, 2011. p. 399-406. Disponível em: <http://www.dsr.inpe.br/sbsr2011/files/p1484.pdf>. Acesso em: 12 abr. 2014.

LONGHITANO, George Alfredo. VANTS para sensoriamento remoto: Aplicabilidade na avaliação e monitoramento de impactos ambientais causados por acidentes com cargas perigosas. 2010. $148 \mathrm{f}$. Dissertação (Mestrado) - Escola Politécnica da Universidade de São Paulo, São Paulo, 2010.

MEDEIROS, Fabricio Ardais. Desenvolvimento de um Veículo Aéreo Não Tripulado para Aplicação em Agricultura de Precisão. 2007. 148 f. Dissertação (Mestrado) - Univresidade Federal de Santa Maria, Santa Maria, 2007.

MOLIN, José Paulo. Agricultura de Precisão: Boletim Técnico. Brasília: 2013. ISBN 978-85-99851-90-6. Disponível em: <http://www.agricultura.gov.br/arq_editor/Boletim Técnico AP.pdf>. Acesso em: 15 abr. 2014.

RASI, Jose Roberto. Desenvolvimento de um Veículo Aéreo Não Tripulado para aplicação em pulverização agrícola. 2008. 70 f. Universidade Federal de Pelotas, Pelotas, 2008.

[1] Professor Dr. $1^{\circ}$ Ten. no Instituto de Logística da Aeronáutica -ILA, Pós-Doutor em Administração de 


\section{Empresas FEA/RP-USP}

[2] Doutorando em Engenharia Ambiental USP- São Carlos. Professor e $1^{\circ}$ Ten. da Academia da Força Aérea.

[3] Professor Dr. do Programa de Pós-Graduação Stricto Sensu em Gestão e Inovação na Indústria Animal da FZEA/USP.

\section{PUBLIQUE SEU ARTIGO CIENTÍFICO EM:}

https://www.nucleodoconhecimento.com.br/enviar-artigo-cientifico-para-submissao 